\title{
Studies on the Development of the Ovaries of the Malaria Mosquitoes (Anopheles pharoensis)
}

\author{
Abeer S. Yamany*
}

Zoology Department, Faculty of Science, Zagazig University, Zagazig, Egypt

\begin{abstract}
Age determination technique of mosquitoes was described for An. pharoensis Theobald from Egypt by observing the ovarian changes before and through the gonotrophic cycles. During this ovarian development cycle, seven growing stages of the oocyte were observed in the adult stage. Two distinct periods of egg follicle growth, the previtellogenesis and vitellogenesis, were seen first. The gradual increase in the oocyte size during these phases was attributed to yolk deposition. During vitellogenesis, the oocyte and nurse cell nucleus were similar in size (stage I). Then, the oocyte enlarged and occupied one third of the egg follicle, while the nurse cell (NC) occupied the remaining two thirds. At this phase, the yolk granules (stage III) enlarged, occupying about half of the egg follicle, while the NC contained the other half (stage IV). An increase and accumulation of yolk granules led to the filling of about three fourths of the egg bulk and made the oocyte nucleus hardly visible during stage $\mathrm{V}$. The oocyte undergone a remarkable growth, occupying nine tenth of the length of the follicle in stage VI. Stage VII corresponded to a mature cigar shaped egg and contained two kinds of yolk globules: a large one and a small one. The oocyte and the NC at all stages were surrounded by a single layer of epithelial cells which increased in number, forming the vitelline membrane and the chorion. The mitochondria in the NC, oocyte, and follicular epithelium appeared in light microscopy as granules of different sizes. The Golgi apparatus appeared in different sizes and shapes, since in the early stages of development, it is restricted to the perinuclear zone. When the development proceeded, it enlarged in size, spread over the whole cytoplasm, and participated in the formation of the yolk.
\end{abstract}

Keywords: Mosquitoes; Anopheles ovarian development; Oogenesis

\section{Introduction}

Anopheles pharoensis Theobald found to be the prevalent manbiting anopheline mosquito and the important vectors of malaria and several arboviruses. Determination of the physiological age of the females enables us to establish the number of blood-meals the females have taken. The full blood-meal is necessary for the maturing of one batch of eggs. The whole period from the beginning of one blood-meal to the next includes three phases: (1) the searching for a host and the obtaining of the blood-meal; (2) digestion of the blood and egg formation; and (3) the search for breeding- places and ovipositions. These phases comprise one gonotrophic cycle. The number of gonotrophic cycles undergone by each female represents her physiological age. The ability to determine the duration of each gonotrophic cycle made it possible to assess also the calendar age of the vector. Christopher's stages of ovarian development are redefined in An. pharoensis to provide a more useful description of mosquito physiology. For almost half a century, entomologists worked on problems connected with the determination of the physiological age of insects that are vectors of diseases (especially mosquitoes). Some investigators presented evidence which made it clear that maturation of the oocytes in mosquitoes results from a connection between the process of blood digestion and the development of the ovaries. Important progress has been achieved by Christophers [1,2], Nicholson [3], Nath [4], Woke [5], Beklemishev [6], Detinova [7,8], Polovodova [9], Macan [10], Clements [11], Volozina [12], Kawai [13], Bellamy and Bracken [14], Shalaby [15], Watts and Smith [16], Carneval et al. [17], Lea et al. [18], Ahmed [19], Clements and Boocock [20] and Adham et al. [21]. The description of the sequence of the ovarian development in the malaria mosquito An. Pharoensis using the light and electron transmission microscopic examination was advocated to identify the functional changes include those which were repeated during the development of each batch of eggs. The increase in the over-all dimensions of the ovaries caused by the development of the follicles and the accumulation of yolk granules has been used as a basis in this work.

\section{Materials and Methods}

Mosquitoes of An. pharoensis (Say) used during this study were obtained from a laboratory colony maintained for more than 15 generations in the institute of Medical Entomology, Egypt. Newly emerged adults of An. pharoensis were placed in separate cages, which were made of floors and roofs from glass and all other sides were made from cloth. Adults were supplied with $10 \%$ sucrose solution in cotton pads. The mosquitoes were maintained at $25 \pm 1^{\circ} \mathrm{C}, 70-80$ $\% \mathrm{PH}$ and a photoperiod of 12L: 12D. For oviposition a small white rectangle enamel pans $(4 \times 4 \times 9 \mathrm{~cm})$ was used, then the hatched larvae were transferred to large rectangular pans $(12.5 \times 17.5 \mathrm{~cm})$ containing about $350 \mathrm{cc}$. distilled water, which must be changed daily while the larvae were in the first and second instars and then transferred to a larger pans then left until pupation. However careful cleaning of the dishes was carried out daily to prevent the formation of the scum on the surface of water. Care was taken to compensate breeding water lost through evaporation.

Sucrose fed females were removed from the cages and dissected at intervals of $0 \mathrm{~h}$ (newly emerged), $8 \mathrm{~h}, 16 \mathrm{~h}, 24 \mathrm{~h}$ and $48 \mathrm{~h}$. Then the remaining females were allowed to feed blood until repletion on a

*Corresponding author: Abeer S. Yamany, Zoology Department, Faculty of Science, Zagazig University, Zagazig, Egypt, E-mail: emarewan@yahoo.com

Received January 20, 2012; Accepted April 24, 2012; Published April 26, 2012

Citation: Yamany AS (2012) Studies on the Development of the Ovaries of the Malaria Mosquitoes (Anopheles pharoensis). J Vaccines Vaccin 3:1345 doi:10.4172/2157-7560.1000135

Copyright: () 2012 Yamany AS. This is an open-access article distributed under the terms of the Creative Commons Attribution License, which permits unrestricted use, distribution, and reproduction in any medium, provided the original author and source are credited. 

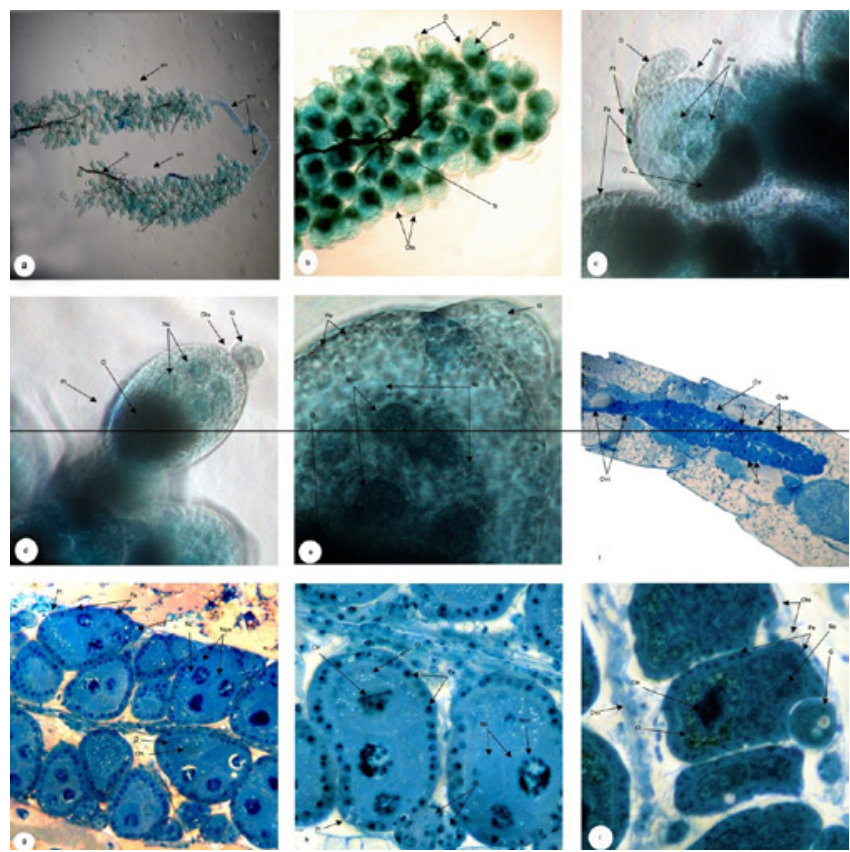

Figure 1: Light micrographs of the first adult phase of An. Pharoensis after emergence $24 \mathrm{~h}$. Methylene blue stain; $\times 10$ (a). Light micrographs of the fourth adult phase after blood meal $24 \mathrm{~h}$. Methylene blue stain; $\times 20(\mathrm{~b}), \times 40$ (c), $\times 40(d), \times 100(e)$. Light micrographs. Semithin longitudinal section of the third adult phase of An. Pharoensis after blood meal $8 \mathrm{~h}$ (f, $\mathrm{g}$ and $\mathrm{h}$ ) and $16 \mathrm{~h}$ (i). Methylene blue stain; $\times 10$ (f), $\times 20$ (g), $\times 40$ (h and i). Showing that Af anterior filament, F1 primary follicle, FE follicular epithelial cell, FEN follicular epithelial cell nucleus, G germarium, NC nurse cell, NCN nurse cell nucleus, O oocyte, ON oocyte nucleus, OLS ovariolar sheath, OV ovary, OVI oviduct, OVS ovarian sheath, TR tracheoles, $Y$ yolk granules, Y1 large yolk spheres, Y2 small yolk spheres.

guinea-pig. Then they were dissected at intervals of $0 \mathrm{~h}$ (immediately after feeding), $8 \mathrm{~h}, 16 \mathrm{~h}, 24 \mathrm{~h}, 32 \mathrm{~h}, 40 \mathrm{~h}, 48 \mathrm{~h}, 56 \mathrm{~h}, 64 \mathrm{~h}$ and $72 \mathrm{~h}$. The sucrose solution (10\%) was removed 6 hours before host exposure under dissecting microscope (Olympus Tokyo, Japan). The ovaries were isolated by tearing off the soft cuticle between the fifth and sixth abdominal sternites with a fine needle, pulling off and placing the terminal segments in a drop of suitable buffer mosquito saline [22] to avoid hyperosmotic reaction. The dissected ovaries were stained with methylblue solution which stains the yolk granules deeply, then placed in a drop of saline, and covered with a cover slip before being microscopically examined in order to determine the stage of follicular development. For Electron microscopic examination, the sugar-fed as well as blood-fed female mosquitoes were fixed in glutaraldehyde and prepared according to Luft [23], dissection was avoided because of the small size of the ovaries, and thus this has the advantage of having the ovaries held in position by the viscera.

\section{Results}

As all Diptera, the ovaries of An. Pharoensis are of the polytrophic type, each ovary is surrounded by two sheaths (the ovarian sheath and ovariolar sheath, Figure 1). In the developmental stages, each ovariole consists of four distinct partitions: terminal filament, germarium, follicle, and pedicel. A follicle contains one oocyte and seven nurse cells. The oocyte is undifferentiated from the nurse cells. Each follicle comes away from the germerium. The epithelium of the newly separated follicle is always less developed than in a mature follicle. Seven growing phases of the oocyte are observed in the adult stage. As two distinct periods of egg follicle growth, the previtellogenesis and vitellogenesis, the gradual increase in the oocyte size during these phases is attributed to yolk deposition.

\section{The Previtellogenesis (First Third Stage)}

\section{Stage I}

In the just emerged, unfed, nulliparous females, the primary follicle (F1) was partially separated from the germarium and the oocyte was not entirely surrounded by the follicular epithelium (FE; Figure 1). The primary follicle (F1) which was almost spherical and which may differentiate into a single small oocyte that was not entirely surrounded by epithelium. Seven undifferentiated nurse cells (NC) were present, tightly packed together, and separated from its neighbor by a definite cell boundary. Each Nurse Cell Nucleus ( $\mathrm{NCN}$ ) contained a clear pycnotic nucleus that was surrounded by a small amount of cytoplasm. The Chromatin $(\mathrm{CH})$ of the $\mathrm{NCN}$ appeared in the form of irregular fragments on a fine network. The Golgi Apparatus (GA) appeared as argentophilic bodies of different sizes and shapes (short rods, granules, spheres, rings, and crescents). The oocytes were randomly scattered by minute argentophilic granules, which increased in number and enlarge in size. The GA formed a network surrounding the nucleus when studied with transmission electron microscopy (Figure 1).

\section{Stage II}

Forty-eight hours after emergence. Several changes had occurred in the histological structure of the ovarioles: the primary follicle (F1) completely separated from the germarium and increased in size and the oocyte was entirely surrounded by the FE which was enlarged with a distinct cell boundary showing a small amount of cytoplasm and a large nucleus. The oocyte was situated in the distal portion of the follicle which retained its spherical shape or became slightly ovoid. Seven NC were seen above the oocyte. As soon as the oocyte is differentiated from its NC, the NC appears relatively larger containing a low amount of cytoplasm. The NCN showed dense $\mathrm{CH}$ material which has condensed to a number of irregular lumps or was scattered throughout the nucleus. The oocyte had increased in size reaching almost the size of the NC, containing a large amount of granular cytoplasm, while its Oocyte Nucleus (ON) was spherical showing a central patch of faintly stained nucleoplasm and a single nucleolus of moderate size, the mitochondria become visible and appeared as granules or short rods. They are perinuclearly distributed around the large nucleus which contains one prominent central nucleolus at this stage. In some cells, the mitochondria appeared as threads among granular ones or retained their rod-like shape. In the oocyte and in the NC, mitochondria showed a tendency to concentrate around the nucleus. The GA of the NC and oocyte developed into a net of tortuous short threads around the nucleus and spread throughout the whole cytoplasm.

\section{Stage III}

The primary follicle (F1) increased in size. The oocyte started to enlarge and became completely separated from the remaining NC occupying about one third of the egg follicle, meanwhile the NC occupied the remnant two thirds. The $\mathrm{NCN}$ was surrounded by a large mass of cytoplasm being limited by a typical membrane cell. The cytoplasm of each NC appeared granular. The oocyte possessed a nearly spherical nucleus, which was surrounded by a layer of dense cytoplasm with a fine texture (Figure 1). Very small refractile lipid droplets were observed in the ooplasm. The nuclear membrane and nucleolus of the oocyte's nucleus were distinct. The GA in the 

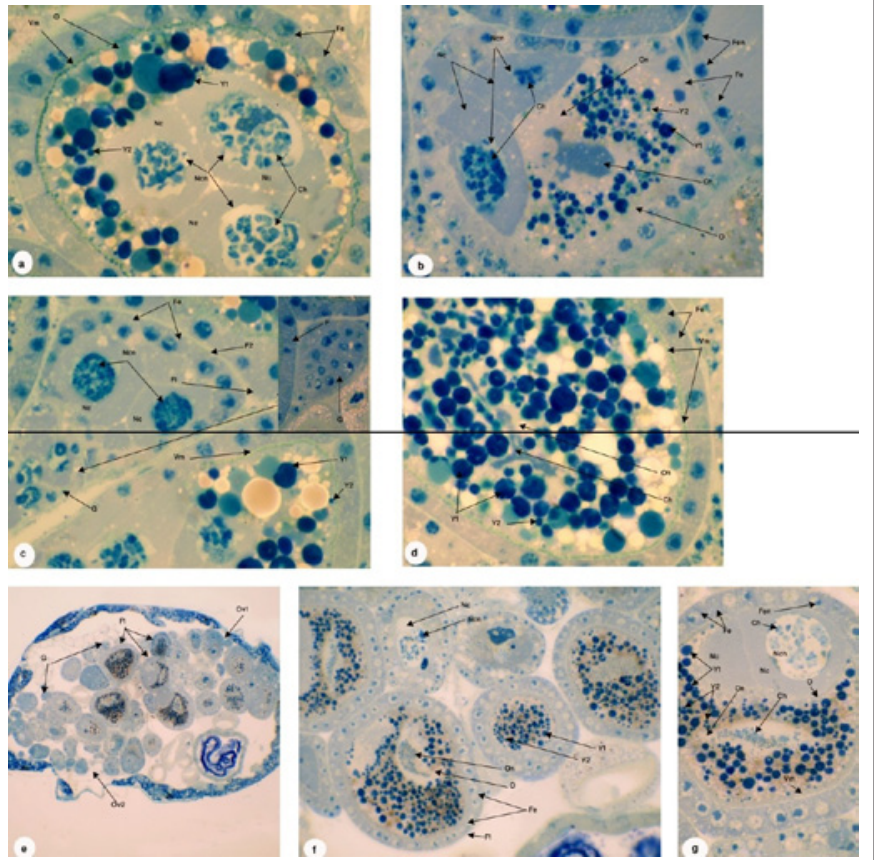

Figure 2: Light micrographs. Semithin longitudinal section of the fourth adult phases of An. Pharoensis after blood meal $24 \mathrm{~h}(\mathrm{a})$ and $32 \mathrm{~h} \mathrm{(b,} \mathrm{c,} \mathrm{and} \mathrm{d).}$ Methylene blue stain $\times 100$. Light micrographs of the fifth adult phase after blood meal 40 h. Methylene blue stain; $\times 20$ (e), $\times 40$ (f), $\times 100$ (g). Showing that $\mathrm{CH}$ chromatin, ENC endochorion, EXC exochorion, F1 primary follicle, FE follicular epithelial cell, FEN follicular epithelial cell nucleus, G germarium, MY micropyle pore, NC nurse cell, NCN nurse cell nucleus, O oocyte, ON oocyte nucleus, VM vitelline membrane, Y1 large yolk spheres, Y2 small yolk spheres.

NC underwent a very tight clumping (Figure 4).

\section{Vitellogenesis (Fourth Seventh Stage)}

\section{Stage IV}

After the blood meal, one or two rows of yolk granules surrounded the nucleus. As soon as small particles of yolk were deposited inside the cytoplasm of the oocyte, they increased until the cytoplasm was completely filled with yolk. While the follicle increased in size, and became ovoid, the FE was still provided with a large nucleus and a small amount of cytoplasm. The NC occupied about half of the egg follicle. The oocyte increased in size occupying about half of the egg follicle. The ON had a central position and was surrounded by a yolk-free cytoplasm. Furthermore, the ON contained a central mass of $\mathrm{CH}$. Some changes started at the nuclear membrane of the oocyte, which appeared now irregular at its surface forming a few invaginations into the cytoplasm.

The number of the follicular epithelial cells increased. Lipid droplets became visible in the ooplasm as well as yolk depositions occurred in addition to some structural changes in the primary follicle. The mitochondria increased in number and the GA in the NC appeared as small granules or groups of them. Some appeared in the light microscopy as short strings of loosely connected beads or rings. The GA in the oocyte was adherent to the outer surface of the yolk spheres or was situated between them (Figure 2 a, b, c and d).

\section{Stage V}

As oogenesis proceeded, the follicle increased in size and became ovoid in shape, The NC nuclei reached their maximum size and appeared with a maximum degree of undulation of the nuclear membrane. During progressive development, the yolk spheres increased in number and size filling about three fourths of the egg, hiding the nucleus of the oocyte. Large densely packed yolk spheres $\mathrm{Y} 1$ as well as small ones $\mathrm{Y} 2$ occurred at the broad anterior end of the oocyte (Figure 2e, f and g). The epithelial cells surrounded the NC became more or less enlarged, while those surrounding the oocyte were still large, cuboidal, and were separated from each other by intercellular spaces. The vitelline membrane (VM) that adhered to both the oocyte and FE now became visible, but was only secreted until yolk formation was completed (Figure 2e, f and g, 5a, b and c). Showing that $\mathrm{CH}$ chromatin, ENC endochorion, ER endoplasmic reticulum, EXC exochorion, F1 primary follicle, FD fat droplet, FE follicular epithelial cell, FEN follicular epithelial cell nucleus, FM follicular membrane, FT float, G germarium, GA Golgi apparatus, GL glycogen, M mitochondria, MY micropyle pore, NC nurse cell, NCN nurse cell nucleus, $\mathrm{O}$ oocyte, $\mathrm{ON}$ oocyte nucleus, SV secretory vesicle, VM vitelline membrane, Y1 large yolk spheres, Y2 small yolk spheres.

\section{Stage VI}

The oocyte underwent growth, increased, occupying nine tenth of the follicle. The ON was formed at the extreme anterior end and just below the VM and the NC (Figure $3 \mathrm{~b}$ and c). The micropyle cup appeared on the egg. As a result of the elongation of the oocyte, the follicular Epithelial Cells (FE) was also elongated with the expanding surface of the oocyte and became spindle-shaped (Figure $3 \mathrm{~b}$ and $\mathrm{c}$ ). A decrease in the number of the follicular epithelial cells was observed. The continuous VM was formed as a thick layer although it remained rather thin between the oocyte and the NC. There was no longer a FE between the NC and the oocyte. The GA in the NC appeared in light microscopy as unconnected individual granules or in the shape of very fine threads being distributed throughout the cytoplasm. In the oocyte, the GA appeared like in the previous stages but with an increase in its quantity.

\section{Stage VII}

In this stage, the follicle reached the shape of the typical cigarshape mature egg (Figure $3 \mathrm{~d}$, e and $\mathrm{f}$ ). The primary follicle (F1) increased in size. Due to degeneration and disappearance of the
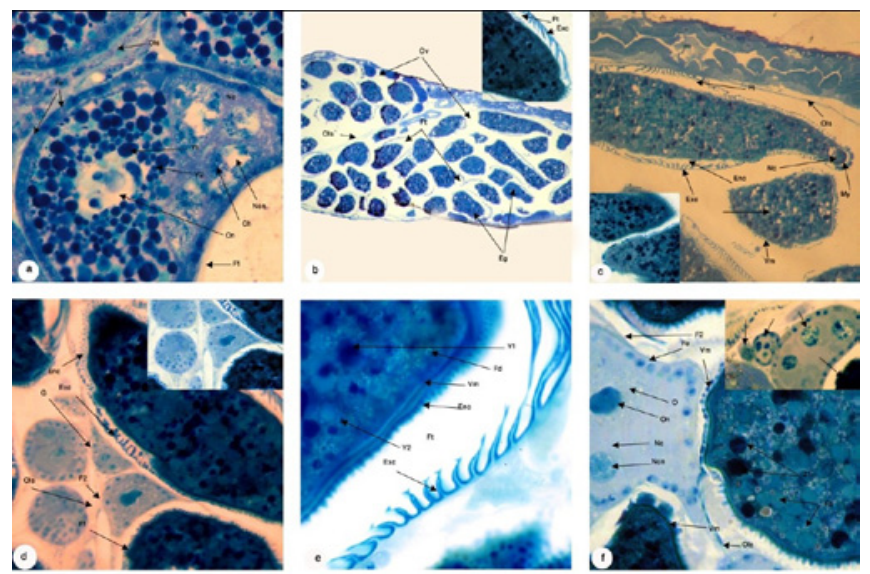

Figure 3: Light micrographs. Semithin longitudinal section of the fifth adult phase of An. Pharoensis after blood meal in $48 \mathrm{~h}$ (a). Methylene blue stain $\times 100$. Light micrographs. Semithin longitudinal section of the sixth adult phase of $A n$. Pharoensis after blood meal in $64 \mathrm{~h}$ (b and c). Methylene blue stain $\times 20$ (b), $\times 40$ (c) and of the seventh adult phase after blood meal in $72 \mathrm{~h}$ (d, e and f). Methylene blue stain, $\times 40$ (d), ×100 (e and f). 

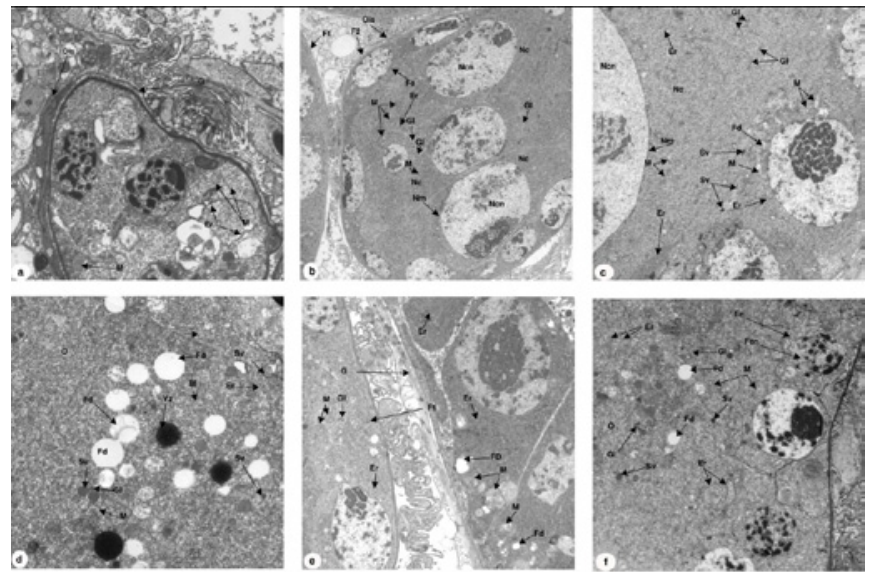

Figure 4: Transmission electron micrographs of the third adult phase of the An. Pharoensis after blood meal in $8 \mathrm{~h}$ ( $\mathrm{a}$ and $\mathrm{b} \times 7,000 ; \mathrm{c}$, d, e and $\mathrm{f}, \times 12,000$ ). Showing that $\mathrm{CH}$ chromatin, ENC endochorion, ER endoplasmic reticulum, EXC exochorion, FD fat droplet, FE follicular epithelial cell, FEN follicular epithelial cell nucleus, GA Golgi apparatus, GL glycogen, M mitochondria, NC nurse cell, NCN nurse cell nucleus, O oocyte, OLS ovariolar sheath, ON oocyte nucleus, SG secretory granules, SV secretory vesicle, VM vitelline membrane, Y1 large yolk spheres, Y2 small yolk spheres.

NC, only the oocyte occupied the primary follicle. The mature egg showed three main regions: the yolk mass, the VM, and the chorion (Figure $5 \mathrm{~d}$, e and $\mathrm{f}$ ). The yolk mass occupied the whole interior of the egg inside the VM. Two kinds of yolk spheres occurred as large globules (Y1) and small spheres (Y2) (Figure 3d, e and f). The VM retained its full thickness. The follicular epithelial cells disappeared after the formation of the VM and the complete deposition of yolk. The secretion and positioning of the chorion occurred. It was composed (1) of an inner narrow homogeneous layer, the endochorion (ENC), which seemed to be composed of two layers and a granular filamentous layer, and (2) the exochorion (EXC), which was composed of several layers (Figure $3 \mathrm{~d}, \mathrm{e}, \mathrm{f}, 5 \mathrm{~d}$, e and $\mathrm{f}$ ). The FE between the NC and the oocyte had disappeared. The cytoplasm of the oocyte appeared as a net-like structure with the mitochondria being attached to the interlacing threads. When the cytoplasm was entirely filled with yolk spheres, the mitochondria granules were still occupying the space between the large yolk spheres. In the oocyte, the GA appeared in light microscopy as complete or broken globules adhering to the outer surface of the yolk spheres.

\section{Discussion}

The present study revealed that the stages of development of the ovary of An. Pharoensis are divided into two periods: the previtellogenesis stages comprising the first until the third stages seen during the first 3 days after emergence, while the vitellogenesis was initiated as soon as the female had fed blood covering the fourth until the seventh stages. The latter culminated in the final formation of the mature egg. Thus, a single large blood meal was normally sufficient to trigger the completion of ovarian development as was reported by Kawai [13], Bellamy and Bracken [14], Abdel-Ghaffar [24] for $C$. molestus, Carnevale et al. [17], Lea et al. [18] and Adham et al. [21] for C. pipiens quinquefasciatus. However, Christophers [1] reported that the progressive changes in the ovary and ovarioles of mosquitoes may pass only through five phases.

At the moment of the first flight, each ovariole usually consisted of one follicle, above which the germarium is situated. Follicles continue to break away in turn in all the ovarioles throughout the active life of the female, this phenomenon being co-ordinated with the stages of each gonotrophic cycle. The total number of follicles which break away from the germarium starting vitellogenic development is determined by the sexual activity and calendar age of the gonoactive female depending on the amount of available nutrient. The first period was marked by a new follicle leaving the germarium. During this period, a group of two, then four and eight cells appeared in the lower portion of the germarium. Simultaneously with this increase in the member of cells, the FE was arranged around the newly formed follicle. The follicle was partially separated from the germarium and the oocyte was not surrounded by epithelium. Similar observations were reported by Detinova [25], Clements and Boocock [20] for Aedes aegypti, Culex pipiens quinquefasciatus, and Anopheles gambiae and by Adham et al. [21] for C. P. quinquefasciatus.

The relative size of this portion decreased in every following stage. At the end of oocyte development, the FE secreted a gelatinous substance which gave rise to the ENC. The chorion as a whole was formed afterwards. Finally, the follicle was separated from the germarium and the oocyte was distinguishable from the NC by its smaller nucleus and a prominent nucleolus. Similar observations were reported by Ahmed [19] for C. pipiens molestus, by Clements and Boocock [20] for Ae. aegypti, C. p. quinquefasciatus and Ae. gambiae, and by Adham et al. [21] for C. P. quinquefasciatus.

The branching of the nuclear membrane, which started during the formation of the fourth and fifth stages of oogenesis, proceeded in the sixth stage. The nucleus became less conspicuous, since it was closely surrounded by yolk spheres. Similar findings were described by Nicholson [3], Ahmed [19], Clements and Boocock [20] and by Adham et al. [21] for C. p. quinquefasciatus. The follicular epithelial cells elongated due to the growth of the oocyte. The accumulation of yolk granules was first of all around the nucleus of the oocyte (or rather the oogonium), which in its gradual development pushes the nurse
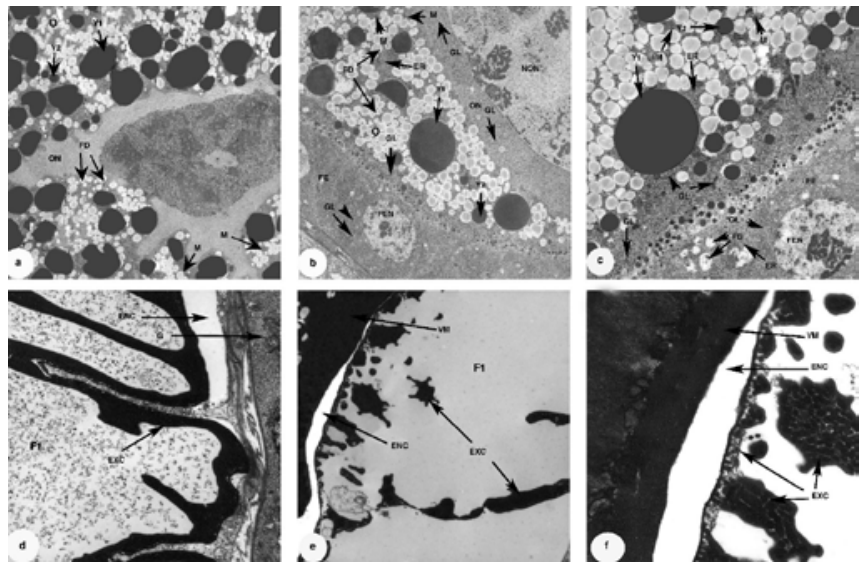

Figure 5: Transmission electron micrographs of the fifth adult phase of the An. Pharoensis after blood meal in $48 \mathrm{~h}(\mathrm{a}, \mathrm{b}$ and $\mathrm{c} \times 7,000$ ). Transmission electron micrographs of the seventh adult phase of the An. Pharoensis after blood meal in $72 \mathrm{~h}$ ( $\mathrm{d}$ and $\mathrm{f} \times 7,000$ and $\mathrm{e} \times 4,400$ ) Showing that $\mathrm{CH}$ chromatin, ENC endochorion, ER endoplasmic reticulum, EXC exochorion, FD fat droplet, FE follicular epithelial cell, FEN follicular epithelial cell nucleus, GA Golgi apparatus, GL glycogen, M mitochondria, NC nurse cell, NCN nurse cell nucleus, O oocyte, OLS ovariolar sheath, ON oocyte nucleus, SG secretory granules, SV secretory vesicle, VM vitelline membrane, Y1 large yolk spheres, Y2 small yolk spheres. 
cells up to the proximal end of the follicle. In later stages the follicle grows longer and the oogonium, filled with yolkgranules, becomes considerably bigger and opaque. In the portion previously occupied by the nurse cells a micropyle forms. These observations were consistent with those of Nicholson [3] and with Adham et al. [21], for C. p. quinquefasciatus. However, Detinova [8] stated that the follicular cells were composed of a regular cuboidal epithelium. Samarawickrema [26] stated that the follicular epithelial cells of Mansonia sp. are cuboidal in the young follicle, but when the follicle elongated, the epithelium progressively shrinked in thickness. At the final stages of growth, the epithelium was very thin. Bertram [27] reported that, throughout the developmental stages of mosquito, the FE became progressively thinner and is finally reduced into groups of disintegrated cells difficult to be detected.

In the first and second stages of ovarian development, the mitochondria was perinuclearly distributed, forming a ring that surrounded the comparatively large nucleus with its prominent central nucleolus. The fate of the nurse cells which remained outside the chorion when egg development was completed, after ovulation the remains of the nurse cells were seen in the ovarioles as yellowish droplets (their presence is one of the signs distinguishing a female which has just laid its eggs from a nulliparous female) these observations were consistent with Beklemishev [6] for An. maculipennis and with Adham et al. [21], for C. p. quinquefasciatus.

In the third or fourth stages of ovarian development, the mitochondria increased in number and were distributed in the cytoplasm where they participated in the formation of yolk. When the cytoplasm was entirely filled with yolk spheres, the mitochondria granules were still present. These results were in agreement with those of Hafez (1981) [28], Ahmed [19] for C. pipiens molestus and Adham et al. [21], for C. p. quinquefasciatus.

The follicle was transparent only at the top, where the nurse cells lie. The relative size of this portion decreased in every succeeding phase and at the end of the development the nurse cells were outside the egg chorion. These observations were consistent with those of Detinova [25] and Adham et al. [21] for C. p. quinquefasciatus.

The follicular epithelium secreted a gelatinous substance which gave rise to the endochorion and the chorion as a whole was formed afterwards. In the centro-lateral part of the follicle the cells of the follicular epithelium, arranged in two symmetrical groups, became larger and give rise to the floats. These results were in agreement with Adham et al. [21], for C. p. quinquefasciatus.

The ovariole was enclosed in an internal membrane or intima closely adhering to the germarium and the follicles. At its distal end the intima forms the efferent portion of the ovariole. This efferent portion called terminal pedicle. This terminal pedicle consists of a fine hollow tubule with scarcely perceptible constrictions, of which the form and dimensions didn't change until the end of the first gonotrophic cycle, these observations were consistent with those of Detinova [7] and Adham et al. [21] for C. p. quinquefasciatus.

\section{Acknowledgment}

The author expresses her gratitude to Prof. Dr. Heinz Mehlhorn, Head of Institute of Parasitology, Cell biology and Zoology, Hein-Rich Heine University, Dusseldorf, Germany for his encouragement and interested me in the Institute for working this research and Prof. Dr. Fatma K. Adham for her encouragement.

\section{References}

1. Christophers SR (1911) The development of the egg follicle in Anophelines. Paludism 2: 73-88

2. Christophers SR (1923) The structure and development of the female genital organs and hypopygium of the mosquito. Ind Med Res X: 698-720.

3. Nicholson AJ (1921) The development of the ovary and ovarian egg of a mosquito, Anopheles maculipennis, Meig. Q J Microsc Sci 65: 395-448.

4. Nath VM (1924) Egg-follicle of Culex. Q J Microsc Sci 65: 152-175.

5. Woke PA (1937) Comparative effects of the blood of different species of vertebrates on egg-production of Aedes aegypti (Lin.). Am J Trop Med 17: 729745 .

6. Beklemishev WN (1944) Ecology of the malaria. Medgiz, Moscow.

7. Detinova TS (1949) Physiological changes of ovaries in females of An maculipennis. Med Parazitol Parazit Bolezni 18: 410.

8. Detinova TS (1962) Age-grouping methods in Diptera of medical importance with special reference to some vectors of malaria.. Monogr Ser World Health Organ 47:13-191.

9. Polovodova VP (1949) Age changes in the female reproductive system of Anopheles and age composition of mosquito populations, Rostov-on-Don (thesis).

10. Macan TT (1950) The Anopheline mosquitoes of Iraq and North Persia Memoires of the London School of Hygiene and Tropical Medicine 7: 109-223.

11. Clements AN (1963) The physiology of mosquitoes. Macmillan, New York 393 p.

12. Volozina NV (1967) The effect of the amount of blood engorged and of supplementary carbohydrate feeding on the process of oogenesis in the females of blood sucking mosquitoes in the genus Aedes. (Diptera: Culicidae) of different weights and ages. Entomol Obozr 46: 49-59.

13. Kawai S (1969) Studies on the follicular development and feeding activity of the females of Culex tritaeniorhynchus with special reference to those in autumn. Trop Med (Nagasaki) 11: 145-169.

14. Bellamy RE, Bracken GK (1971) Quantitative aspects of ovarian developmen in mosquitoes. Can Entomol 103: 763-773.

15. Shalaby AM (1971) Changes in the Ovaries of Anopheles multicolor and Anopheles pharoensis (Diptera: Culicidae) Following Oviposition. J App Entomol 69: 187-197.

16. Watts RB, Smith SM (1978) Oogenesis in Toxorhynchites rutilus (Diptera: Culicidae). Can J Zool 56: 136 -139.

17. Carnevale P, Molinier M, Bosseno MF, Mouchet J (1978) Rélations mathématiques dans la maturation des follicles ovariens des females parées de Anopheles gambiae (Diptera: Culicidae). Cahiers de I'O.R.S.T.O.M., Serie Entomologie Medical et Parasitologie 16: 121-127

18. Lea AO, Briegel H, Lea HM (1978) Arrest, resorption, or maturation of oocytes in Aedes aegypti (Lin.). A dependence on the quantity of blood and the interval between blood meals. Physiol Entomol 3: 309-316.

19. Ahmed SA (1983) Cytological and cytochemical studies in Culex pipiens molestus (Forskal). Oocyte differentiation and vitellogenesis. MSc Thesis. Fac Science, Alexandria University.

20. Clements AN, Boocock MR (1984) Ovarian development in mosquitoes: stages of growth and arrest, and follicular resorption. Shell Research Limited Sittingbourne Research Centre, Sittingbourne, Kent, pp 18.

21. Adham FK, Mehlhorn H, El-Basheir ZM, Yamany AS (2009) Light and electron microscopic studies on the development of the ovaries of Culex pipiens quinquefasciatus (Say) (Diptera: Culicidae). Parasitol Res 105: 939- 948.

22. Hagedorn HH, Turner S, Hagedorn EA, Pontecorvo D, Greenbaum P, et al. (1977) Postsemergence growth of the ovarian follicles of Aedes aegypti. J Insect Physiol 23: 203- 206.

23. Luft JH (1961) Improvements in epoxy resin embedding methods. J Biophys Biochem Cytol 9: 409-414.

24. Abdel-Ghaffar HA (1978) Functional age changes in the reproductive system of the adult female C. pipiens molestus Forskal (Diptera: Culicidae). PhD Thesis. Fac Science, Cairo University. 
Citation: Yamany AS (2012) Studies on the Development of the Ovaries of the Malaria Mosquitoes (Anopheles pharoensis). J Vaccines Vaccin 3:135 doi:10.4172/2157-7560.1000135

Page 6 of 6

25. Detinova TS (1962) Age-grouping methods in Diptera of medical importance with special reference to some vectors of malaria. Monogr Ser World Health Organ 47: 13-191.

26. Samarawickrema WA (1962) Changes in the ovario le of Mansonia (Mansonioides) mosquitoes in relation to age determination. Ann Trop Med Parasitol 56: $110-126$
27. Bertram DS (1962) The ovary and ovarioles of mosquitoes. Monogr Ser World Health 47: 195-210.

28. Hafez ES (1981) Reproductive biology of Sparus aurata in the Mediterranean Sea waters of Alexandria. PhD thesis. Fac of Science, Alexandria, Egypt. 